\title{
DERIVATION OF THE INDEX GOVERNING THE SEEPAGE FLOW AND DYNAMIC SIMILARITY CONDITION OF LEVEE FAILURES DUE TO SEEPAGE FLOW
}

\author{
SHOJI FUKUOKA \& KOSUKE TABATA \\ Research Development Initiative, Chuo University, Japan
}

\begin{abstract}
It is necessary to establish an estimation method of levee weak points due to seepage flow during floods to make appropriate levee reinforcements and risk management measures in a river basin, preparing for large-scale floods. The internal flow with large phreatic surface gradient in the body of the levee tends to concentrate around the landside toe of the levee during a flood event, which may trigger the levee failure. This study shows that the idea of the levee failure is effective for primary selection of dangerous levee failure positions to the seepage flow. First, the only dynamic index governing the seepage flow in soils, the Seepage Flow number $\left(S F_{n}\right)$, is derived by nondimensionalizing Richards' governing equation for a general seepage flow. Next, by applying $S F_{n}$ to the seepage flow in the levee, the levee vulnerability index $\left(t^{*}\right)$ is derived in the expression of a dynamic dimensionless quantity. Also, the vulnerability index of the levee on the permeable foundation is derived by using the unsteady quasi two-dimensional seepage flow analysis method. Finally, the vulnerability index $\left(t^{*}\right)$ is calculated for the actual field levee and model levee experiment in which each failure mode such as leakage, sliding or collapse and breach occurred. As a result, it is confirmed that $t^{*}$ shows approximately common values in the field levee and model levee taking the same failure mode. Therefore, it is demonstrated that $t^{*}$ gives a dynamic similarity condition on the levee failure phenomena, due to the seepage flow and the judge of the degree of levee failures.

Keywords: seepage flow number, seepage line, levee failure, levee vulnerability index, dynamic similarity law, unsteady quasi two-dimensional equation, prototype and model.
\end{abstract}

\section{INTRODUCTION}

It is necessary to establish an estimation method of levee weak points due to seepage flow during a flood event to make appropriate levee reinforcements and risk management measures in a river basin. A general evaluation method of the levee safety was to calculate the danger of the slope sliding or collapse failure, for the steady seepage line assumed that a certain water level of the flood acts for a long time [1]. However, the internal flow with a large phreatic surface gradient in the body of the levee develops through the soil toward the landside toe during a flood event. The danger of levee failure will rise considerably if the seepage flow abnormally concentrates around the landside toe. Therefore, it will be possible to estimate when, where and what kind of levee failures will occur if the degree of concentration of the seepage flow at the landside toe can be appropriately evaluated.

In this study, the seepage phenomenon in the levee is expressed by the continuity equation and Darcy's law as the equation of motion. First, the index governing the seepage flow in the soil, the Seepage Flow number $\left(S F_{n}\right)$, is derived by nondimensionalizing Richards' governing equation [2] for a general seepage flow. Next, by applying the $S F_{n}$ to the seepage flow in the body of the levee, the levee vulnerability index $\left(t^{*}\right)$ is derived in the expression of a dynamic dimensionless quantity. Moreover, it is confirmed that $t^{*}$ gives a dynamic similar condition to the model and prototype levee. Also, each damaged level of the leakage, slope sliding or collapse and breach that $t^{*}$ can take is discussed. This paper does not target the piping failure caused by the movement of water and the soil particle in a permeable foundation layer. 


\section{DIMENSIONLESS SIMILARITY INDEX GOVERNING GENERAL SEEPAGE FLOW AND LEVEE VULNERABILITY INDEX}

\subsection{Derivation of the similarity index governing the general seepage flow $\left(S F_{n}\right)$}

First, we derive a general similarity index governing a seepage flow in soils, since the comparison of levee failures are made between field and model levees in following sections.

The research on the similarity law of the seepage flow has been conducted in the 1950-1960s. Bear [3] considered the similarity law of the steady seepage flow by nondimensionalizing the flow continuity equation taking account into the seepage flow velocity expressed by Darcy's law. He proposed two conditions expressing the relationships among the dimensionless scales $x^{\prime}, y^{\prime}, z^{\prime}$ and dimensionless coefficients of permeability $k_{x}^{\prime}, k_{y}^{\prime}, k_{z}^{\prime}$.

$$
\frac{x^{\prime 2}}{k_{x}^{\prime}}=\frac{y^{\prime 2}}{k_{y}^{\prime}}=\frac{z^{\prime 2}}{k_{z}^{\prime}}
$$

Corey et al. [4] suggested a similarity condition by nondimensionalization of Richards' equation [2]. However, it was a study focusing on the vertical seepage flow under the gravitational drainage in the saturated ground, and the pressure head and seepage length were given as one common length. Therefore, the suggested dimensionless value could not be a similarity law of the general seepage flow. Although other several similarity relations [5], [6] in which were expressed by empirically combining the length, permeability and porosity were suggested, the verifications were not enough performed. There is no similarity condition for the seepage flow with generality as far as the authors know.

The governing equation of the seepage flow in the soil is expressed by Richards' equation (eqn (2)),

$$
\frac{1}{\rho} \frac{\partial \rho \lambda S_{r}}{\partial t}-\frac{\partial}{\partial x}\left(k \frac{\partial h}{\partial x}\right)-\frac{\partial}{\partial y}\left(k \frac{\partial h}{\partial y}\right)-\frac{\partial}{\partial z}\left(k \frac{\partial h}{\partial z}\right)=0
$$

where $\rho$ is density of water, $\lambda$ is porosity of soil, $S_{r}$ is degree of saturation, $k$ is coefficient of permeability, $h$ is total head $(=\Psi+z), \Psi$ is pressure head. It is necessary to hold the same equation between the prototype and the model by nondimensionalizing the governing equation for deriving the dynamic similarity law. The dimensionless value of each variable of eqn (2) is given as follows by using each representative value. Here, superscript ' and subscript 0 mean dimensionless and representative quantity, respectively.

$$
\rho^{\prime}=\frac{\rho}{\rho_{0}}, S_{r}{ }^{\prime}=\frac{S_{r}}{S_{r 0}}, \lambda^{\prime}=\frac{\lambda}{\lambda_{0}}, h^{\prime}=\frac{h}{H_{0}}, t^{\prime}=\frac{t}{T_{0}}, k^{\prime}=\frac{k}{k_{0}}, x^{\prime}=\frac{x}{L_{0}}, y^{\prime}=\frac{y}{L_{0}}, z^{\prime}=\frac{z}{L_{0}}
$$

When eqn (2) is arranged taking account into eqn (3), the following dimensionless equation is finally obtained.

$$
\frac{1}{\rho^{\prime}} \frac{\partial \rho^{\prime} \lambda^{\prime} S_{r}^{\prime}}{\partial t^{\prime}}+\frac{1}{S_{r 0}} \frac{k_{0} H_{0} T_{0}}{\lambda_{0} L_{0}^{2}}\left\{-\frac{\partial}{\partial x^{\prime}}\left(k^{\prime} \frac{\partial h^{\prime}}{\partial x^{\prime}}\right)-\frac{\partial}{\partial y^{\prime}}\left(k^{\prime} \frac{\partial h^{\prime}}{\partial y^{\prime}}\right)-\frac{\partial}{\partial z^{\prime}}\left(k^{\prime} \frac{\partial h^{\prime}}{\partial z^{\prime}}\right)\right\}=0
$$

In this dimensionless eqn (4), the dimensionless value enclosed with a red frame ahead of parentheses that settle the second, third and fourth terms in the left side appears. This dimensionless value is defined as $S F_{n}$, which shows the dynamic similarity condition of the seepage flow. If the seepage flow in the field (prototype) and the model have the same value of $S F_{n}$, the seepage flow of both will be dynamically similar. 


\subsection{Derivation of levee vulnerability index $t^{*}$ from $S F_{n}$}

The presented $S F_{n}$ is expressed in the ratio of the time of $S_{r 0} \lambda_{0} L_{0}^{2} / k_{0} H_{0}$ to $T_{0}$. The former indicates the time required to move the representative horizontal distance $L_{0}$ by the true seepage flow velocity $k_{0} H_{0} / S_{r 0} \lambda_{0} L_{0}$. The latter indicates the representative time of the seepage flow.

The $S F_{n}$ can be rewritten in the index that relates the seepage flow in the levee to the levee failure if each representative physical value that consists $S F_{n}$ is chosen properly so as to describe the seepage phenomena in the levee.

By substituting $H, b, t^{\prime}, k, \lambda$ and $S_{r}$ to $H_{0}, L_{0}, T_{0}, k_{0}, \lambda_{0}$ and $S_{r 0}, S F_{n}$ is finally shown by eqn (5). Here, $H$ is water level, $b$ is horizontal length from water front to levee toe of landside, $t^{\prime}$ is duration time from when the water level exceeds the ground level of the landside toe. $k, \lambda$ and $S_{r}$ are averaged permeability, porosity and degree of saturation of the levee (see Fig. 1). Then, $S F_{\mathrm{n}}$ is defined as levee vulnerability index $t^{*}$.

$$
t^{*}=\frac{1}{S_{r}} \frac{k H t^{\prime}}{\lambda b^{2}}
$$

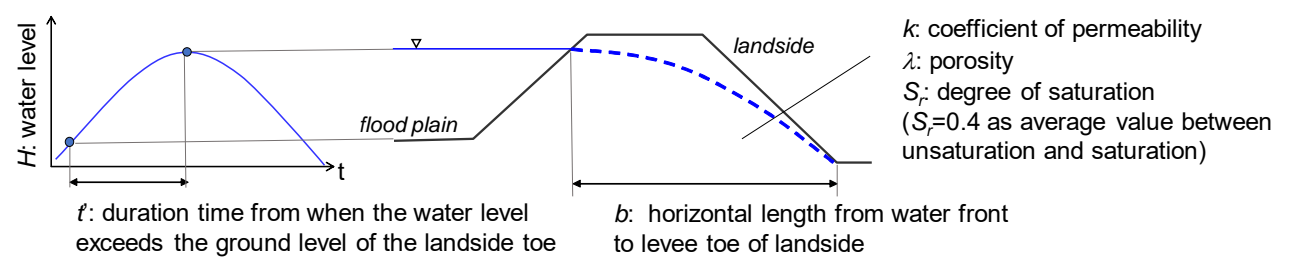

Figure 1: Definition of variables of levee vulnerability index $t^{*}$.

2.3 Derivation of $t^{*}$ from quasi two-dimensional unsteady seepage flow equation

Fukuoka and Tabata [7] assumed the seepage line in the levee on the permeable foundation as the similar function form (eqn (6)).

$$
h(x, t)=H\left\{1-\left(\frac{x}{\xi(t)}\right)^{m}\right\},
$$

where $\xi$ is a front position of seepage line, $m$ is a parameter which defines the shape of the seepage line.

In addition, a differential equation of quasi two-dimensional unsteady seepage flow (see Fig. 2) that can describe the movement of the seepage line was derived based on Darcy's law and continuity condition of water in the levee and foundation. The derived equation was solved for the front position $\xi$ of the seepage line and let $T$ be the time required for the seepage line to reach the horizontal distance $b$. Then, the general levee vulnerability index (eqn (7)) defined by $t^{*}{ }_{\mathrm{m}}=t^{\prime} / T$ was obtained.

$$
t_{m}^{*}=\frac{2(m+1)}{2 m-1} \frac{m k_{1} H-m(2 m-1) k_{2} D}{m H+(m+1) D} \frac{H t^{\prime}}{\lambda b^{2}},
$$


where, $k_{1}$ and $k_{2}$ are the coefficients of permeability of the levee and foundation, $D$ is the thickness of the permeable layer and defined as the distance from the impermeable layer or ground water level to the ground level under the levee. The parameter $\mathrm{m}$ in eqn (6) can be decided by Table 1 , based on the values of $k_{2} / k_{1}$ and $D / H$ of the levee and foundation [7].
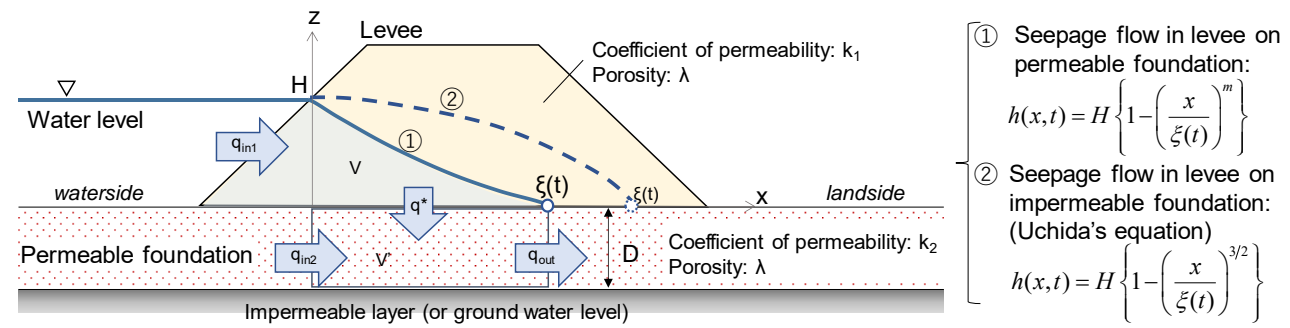

Figure 2: Quasi two-dimensional unsteady seepage flow in the levee [7].

Table 1: Relationship of $k_{2} / k_{1}, D / H$ and parameter $m$ [7].

\begin{tabular}{ccccccccc}
\hline $\begin{array}{c}\mathrm{k}_{2} / \mathrm{k}_{1} \\
\mathrm{D} / \mathrm{H}\end{array}$ & 0 & 0.1 & 0.5 & 1 & 2 & 5 & 10 & 20 \\
\hline 0 & 1.500 & 1.500 & 1.500 & 1.500 & 1.500 & 1.500 & 1.500 & 1.500 \\
0.1 & 1.500 & 1.500 & 1.500 & 1.500 & 1.426 & 1.060 & 0.858 & 0.711 \\
0.5 & 1.500 & 1.500 & 1.472 & 1.075 & 0.823 & 0.660 & 0.588 & 0.545 \\
1 & 1.500 & 1.500 & 1.118 & 0.860 & 0.700 & 0.591 & 0.546 & 0.524 \\
2 & 1.500 & 1.384 & 0.866 & 0.710 & 0.614 & 0.547 & 0.524 & 0.510 \\
5 & 1.500 & 1.014 & 0.671 & 0.592 & 0.549 & 0.519 & 0.509 & 0.504 \\
10 & 1.500 & 0.821 & 0.591 & 0.548 & 0.524 & 0.509 & 0.504 & 0.501 \\
20 & 1.500 & 0.691 & 0.548 & 0.524 & 0.510 & 0.504 & 0.501 & 0.501 \\
\hline
\end{tabular}

In the case of the levee on the impermeable foundation, $D$ and $k_{2}$ in eqn (7) are zero. Also, the parameter $m$ is chosen $3 / 2$ in order to coincide with the one-dimensional unsteady seepage line equation suggested by Uchida [8]. Then, $2(m+1) /(2 m-1)$ in eqn (7) becomes the value of $5 / 2$. As a result, the levee vulnerability index $t^{*}$ of the levee on the impermeable foundation is given by eqn (8).

$$
t^{*}=\frac{5}{2} \frac{H k_{1} t^{\prime}}{\lambda b^{2}}
$$

This equation means that the true seepage flow velocity in the levee is described by $5 / 2 H k_{1} / \lambda b$ when the water level in the river $H$ acts on the unsaturated levee with width $b$, coefficient of permeability $k_{1}$ and porosity $\lambda$. Also, it can be interpreted that the influence of degree of saturation $S_{r}$ in eqn (5), which changes as the seepage line develops, is included in the coefficient $5 / 2$.

Uchida [8] expressed the averaged velocity of the seepage flow in the levee as $8 / 3 H k_{1} / \lambda b$ by solving the temporary change of the seepage line based on the graphical analysis method and confirmed it by seepage flow experiments. Therefore, as the seepage line develops and the effects of saturation and unsaturation in the soil are integrated, finally the moving speed of the seepage line is described by $8 / 3 H k_{1} / \lambda b$ on average. Since the degree of saturation $S_{r}$ of soil is about 0.3 in the completely gravity drained state and 1 in the saturated state, $1 / S_{r}$ of $t^{*}$ 
(eqn (5)) derived from $S F_{n}$ takes about 1 to 3. Therefore, it is can be regarded that eqns (5) and (8) almost coincide. In general, it is known that the permeability coefficient varies according to the degree of saturation, but this paper does not refer to how to incorporate the change in saturation at unsteady seepage phenomena and the corresponding permeability coefficient.

In the case of the levee on the permeable foundation, the time $T$ required for the seepage line to reach the landside toe will be larger compared with the case of the levee on the impermeable one, because a part of water in the levee flows into the permeable foundation and it makes the seepage line lower. For these reasons, the levee vulnerability index $t^{*}{ }_{\mathrm{m}}$ on the permeable foundation is calculated smaller than $t^{*}$ on the impermeable one. Therefore, the levee vulnerability index $t^{*}$ that assumes the impermeable foundation should be applied as the index of a dangerous failure.

The levee vulnerability index $t^{*}$ on the impermeable foundation shown by eqn (8) is described in the same formula form with index (eqn (5)) obtained by applying $S F_{n}$ to the seepage flown in the levee. This means that the levee vulnerability index $t^{*}$ is the only dynamic similarity condition of the seepage flow in the levee.

\section{APPLICATION OF LEVEE VULNERABILITY INDEX}

\subsection{Application of the levee vulnerability index $t^{*}$ to field levees}

The levee vulnerability index $t^{*}$ of the field levees in the Kinu River 2015 flood, the Koyoshi River 2013 flood, the Kakehashi River 2012 flood, the Yabe River 2012 flood and the Nagara River 1976 flood is calculated. In these rivers, the levee damage occurred considerably due to seepage flows during flood events (see Fig. 3(a) and (b)).

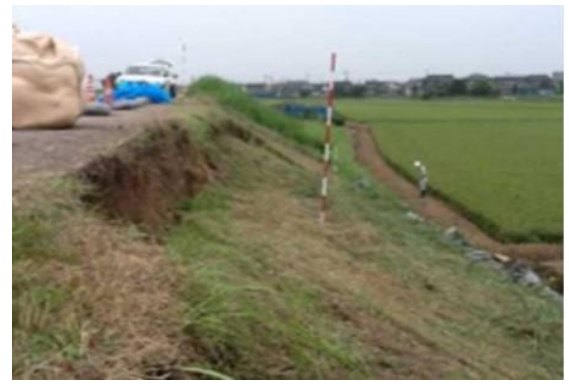

(a)

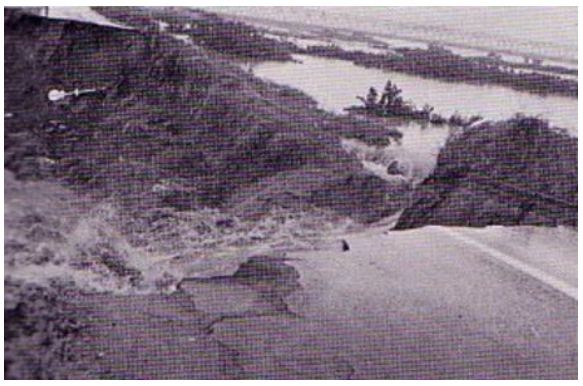

(b)

Figure 3: The levee failure due to the seepage flow observed in the field levee. (a) Sliding at $8.4 \mathrm{k}$ right bank in the Kakehashi river during the 2012 flood; (b) Levee breach at $33.8 \mathrm{k}$ right bank in the Nagara river during the 1976 flood.

Fig. 4 shows the value of the levee vulnerability index of the respective field levee calculated by using eqns (7) and (8). The coefficient of permeability is estimated based on Hazen [9] or Creager et al.'s [10] method, by using $D_{10}$ and $D_{20}$ observed by the boring survey data of the levees and larger one of Hazen and Creager's method is given to the calculation. The calculated $t^{*}$ are plotted with larger variation compared with the model levee experiments stated in 3.2 since the influences of rainfall and slope protection are not taken into consideration. However, the levee vulnerability index $t^{*}$ of the field levee in which the 
levee breach (red circles in Fig. 4) and sliding or collapse (yellow circles in Fig. 4) occurred take approximately $0.1-1.0$ and $0.01-0.1$ respectively. In which the leakage from the levee (without circles in Fig. 4) occurred, the variation of the data is large, but most of the $t^{*}$ are distributed in the range larger than 0.001 .

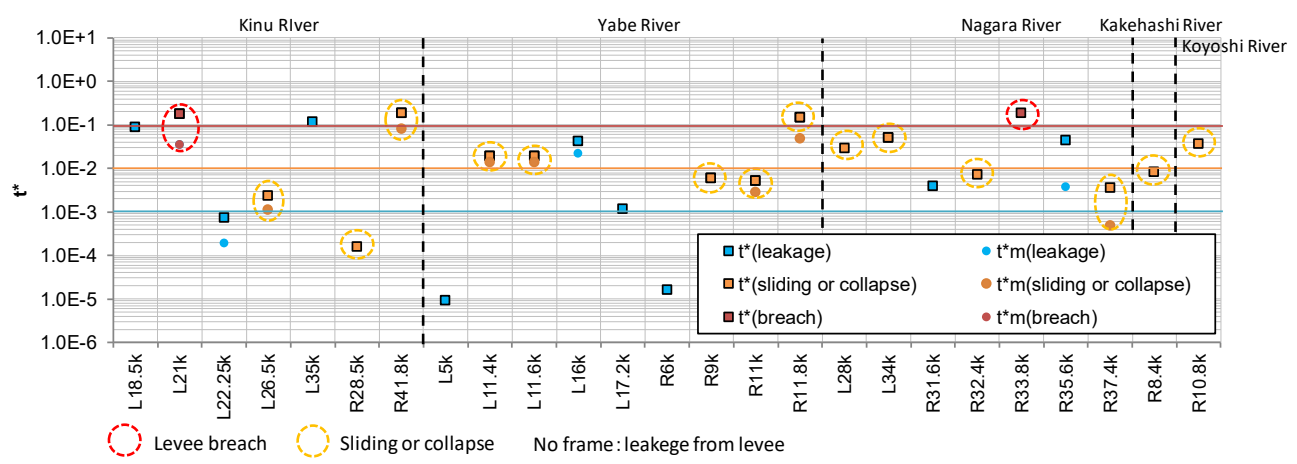

Figure 4: The values of the levee vulnerability index $t^{*}$ of the field levees.

\subsection{Application of the levee vulnerability index $t^{*}$ to model levee experiments}

Yoshikawa and Kodaka [11] conducted a series of model levee experiments for clarifying the relationship between the soil structure and the levee failure mechanism due to the seepage flow. Three kinds of models such as two-dimensional half cross section, two-dimensional full cross section and three-dimensional full cross section were created, and a total of 22 cases of experiments whose thickness and permeability of the foundation layer were different were carried out. Fig. 5 shows the specification of the two-dimensional full section model and example of the levee failure due to the seepage flow observed in the model levee. The model levee is $0.2-0.3 \mathrm{~m}$ in height and $0.7-0.9 \mathrm{~m}$ in width. The foundation is created by the different permeable materials in the upper and lower layer. The outside water level was rapidly increased from the initial water level condition while the lower layer was saturated, then the water level was kept constant. The deformation process of the body of levees and its occurrence time were observed.
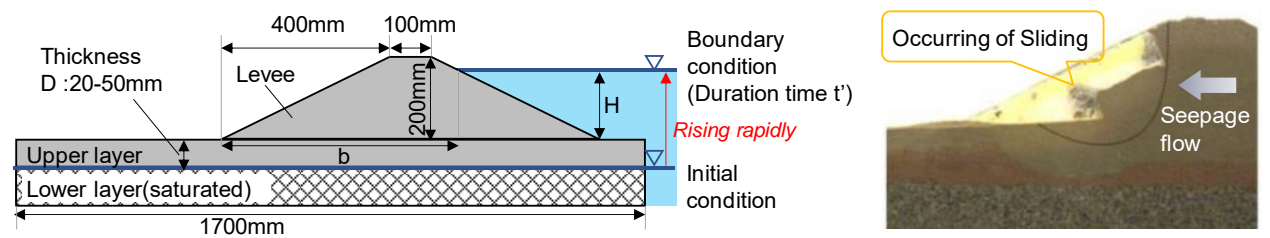

Figure 5: Specification of the two-dimensional full section model levee and example of the levee failure due to the seepage flow observed in the model levee.

By using these experimental data, the relationship between $t^{*}$ and the failure modes is investigated. Fig. 6 shows the values of the levee vulnerability index $t^{*}$ of the model. The levee vulnerability index $t^{*}$ of the experiments in which the levee breached are almost all 
plotted in the range of $0.1-1.0$. In which the sliding or collapse occurred, $t^{*}$ are concentrated at the range of 0.01-0.1 and plotted 16 data at this range. In addition, most of $t^{*}$ calculated for cases which the leakage from the levee are observed are approximately plotted in the range of 0.001 to 0.01 . These results are the same as ones of the field levees in 3.1.

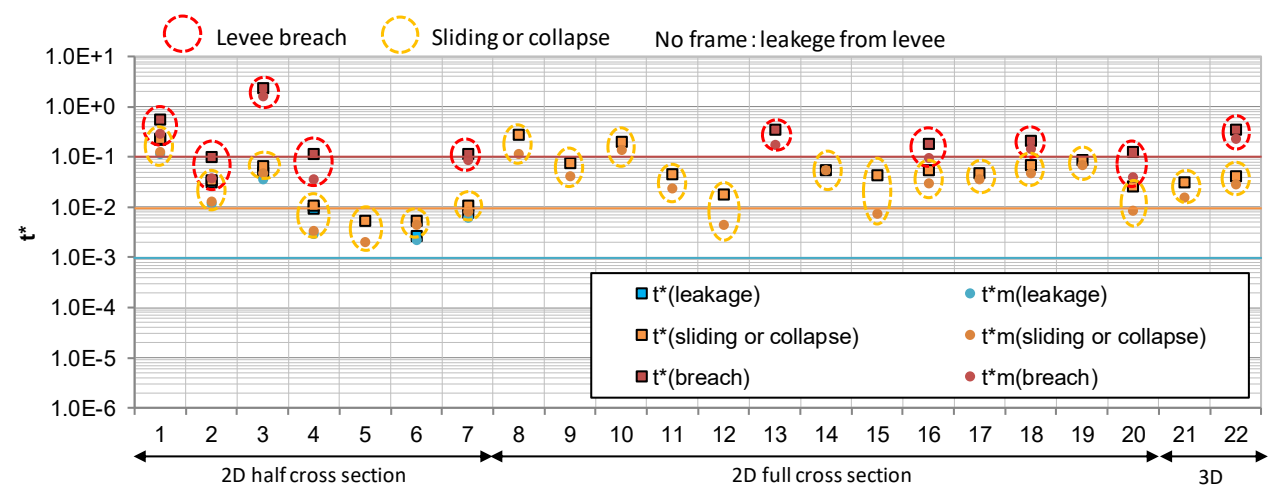

Figure 6: The values of the levee vulnerability index $t^{*}$ of the model levees.

Consequently, $t^{*}$ can approximately elucidate the degree of the levee damage and the danger due to the seepage flow. It is clear that $t^{*}$ is the dynamic similarity condition established commonly for model levees and field levees since the range of $t^{*}$ taken by each failure mode in the field levee and model levee experiment is almost in agreement.

\section{CONCLUSION}

Based on the idea that the internal flow with large phreatic surface gradient in the body of levees concentrates around the landside toe of the levee during a flood event, which may trigger the levee failure, the estimation method for the degree of the levee failure due to the seepage flow is presented. First, the only dynamic index governing the seepage flow in the soil, $S F_{n}$, is derived by nondimensionalizing Richards' governing equation for a general seepage flow. Next, by applying $S F_{n}$ to the seepage flow in the levee, levee vulnerability index $t^{*}$ is derived in the expression of a dynamic dimensionless quantity. Also, the vulnerability index of the levee on the permeable foundation is derived by using unsteady quasi two-dimensional seepage flow analysis method. Finally, the vulnerability index $t^{*}$ is calculated for the actual field levee and model levee experiment in which each failure mode such as leakage, sliding or collapse and breach occurred. As a result, it is confirmed that $t^{*}$ shows approximately common values in the field levee and model levee experiment taking the same failure mode. Therefore, it is demonstrated that $t^{*}$ gives a dynamic similarity condition on the levee failure phenomena due to seepage flow. Also, it is shown that the degree of levee failure can be judged by $t^{*}$ value.

\section{ACKNOWLEDGEMENT}

In this study, we used valuable data of the seepage flow in the model levee experiment conducted by the research group of Professor Takeshi Kodaka of Meijo University, Japan. We would like to express our appreciation. 


\section{REFERENCES}

[1] CIRIA, The International Levee Handbook, C731, London, 2013.

[2] Richards, L.A., Capillary conduction of liquids through porous mediums. Journal of Applied Physics, 1, pp. 318-333, 1931.

[3] Bear, J., Dynamics of Fluids in Porous Media, American Elsevier, pp. 671-677, 1972.

[4] Corey, G.L., Corey, A.T. \& Brooks, R.H., Similitude for Non-Steady Drainage of Partially Saturated Soils, Hydrology Papers 9, Colorado State University, 1965.

[5] Kawaharada, R., On the Hydraulic Similarity of the Unsteady Seepage Flow, Faculty of Agriculture, Kagoshima University, vol. 5, pp. 115-117, 1956 (Japanese).

[6] Nakamura, M., Fundamental theory of motion of percolation water (IV) A theory of model experiment. Journal of the Agricultural Engineering Society, 25-26, 1957 (Japanese).

[7] Fukuoka, S. \& Tabata, K., Development of seepage line estimation method considering permeable foundation ground under the levee and reinforcing against the levee failure. Advances in River Engineering, 22, pp. 261-266, 2016 (Japanese).

[8] Uchida, S., On the non-steady percolation with a free boundary. Japan Society of Civil Engineers, pp. 58-62, 1952 (Japanese).

[9] Hazen, A., Some physical properties of sands and gravels with special reference to their use in filtration, Massachusetts State Board of Health, 24th Annual Report, pp. 539-556, 1892.

[10] Creager, W.P., Justin, J.D. \& Hinds, J., Engineering for Dams, vol. III, John Wiley \& Sons, 1945.

[11] Yoshikawa, T. \& Kodaka, T.A., Consideration of the failure mechanism of river levees due to water seepage based on model tests and soil-water-air coupled finite deformation analysis. Proceedings of the 19th International Conference on Soil Mechanics and Geotechnical Engineering, pp. 1319-1322, 2017. 